ARTICLE INFO

Received

September 17, 2021

Revised

December 04, 2021

Accepted

December 06, 2021

Published

January 11, 2022

*Corresponding author

Syed Muhammad Raza

Email

syedmuhammadraza67@gmai

1.com

Phone

+92-332-4195927

Keywords

Covid-19

Immunity

Vaccine

Emerging disease

SARS-CoV-2

How to cite

Raza SM, Fatima SK, Sajjad

T, Shams-ul-Hap, Masood W,

Ahmad I, Amjad S. Prospects of vaccination against

COVID-19 and road to DNAbased vaccine: a review. Sci Lett 2022; 10(1):1-8
Open Access

\section{Prospects of Vaccination Against COVID- 19 and Road to DNA-based Vaccine: A Review}

\author{
Syed Muhammad Raza ${ }^{1 *}$, Syeda Kainat Fatima ${ }^{1}$, Tehreem Sajjad ${ }^{1}$, \\ Shams-ul-Haq ${ }^{1}$, Wajahat Masood ${ }^{1}$, Ibrar Ahmad ${ }^{1}$, Samina Amjad ${ }^{2}$ \\ ${ }^{1}$ Faculty of Veterinary and Animals Sciences, PMAS-Arid Agriculture University, Murree \\ Road, Rawalpindi, Pakistan \\ ${ }^{2}$ Faculty of Forestry, Range Management and Wildlife, Department of Wildlife \\ Management, PMAS-Arid Agriculture University, Murree Road, Rawalpindi, Pakistan
}

\section{Abstract}

Covid-19 made the countries develop and adopt significant measures to control the spread of disease. For this purpose, firstly countries ordered the public to follow precautions, like, wearing a mask, sanitizer usage, and home quarantine. Then, countries endeavor for the preparation of vaccination started to not only stop the spread but to control and end the coronavirus. These efforts of vaccination started giving benefits in late 2020 and by the end of February 2021, many vaccines were approved conditionally and ready to use, while more were on the way to approval. Apparent from this, there is a great possibility that more clinically proven vaccines will be available on the market in the coming few years. Now, when there is the solution, "The Vaccine", the main point is how to meet the need for the vaccine on a global scale and capital generation for the purchase of vaccine. Till so far, mRNA vaccines are market-available, while DNA-type vaccines are under improvement, being experimented and tested. Because DNA vaccines usually only encode one protein from a pathogen; those may not be as effective if individuals need to mount an immune response to numerous proteins to gain protection, but this can be achieved by combining multiple vaccines. While mRNA vaccines guide the immune system to make a protein that will trigger an immune response without using a live virus and generate longer immunity. 


\section{Introduction}

SARS-COV-2 linked with severe respiratory distress syndrome was first witnessed in the city of Wuhan, China. To date, this virus has devoured millions of lives worldwide [1]. WHO officially announced the outbreak of SARS-COV-2 in China on $31^{\text {st }}$ December 2019, initiated a lockdown in the whole of China progressively [1]. SARS-COV-2 belongs to the coronavirus family, which is enveloped viral agent, spherical in shape and range $80-100 \mathrm{~nm}$ in diameter. Genomic studies revealed the presence of a single RNA strand composed of 26.4 to 31.7 kilobases. This particular agent bears $96 \%$ similarity with the bat coronavirus depicting its zoonotic importance [2]. Vaccination has proven to be a beneficial source of immunity against prevailing pathogens. Since 1950, vaccination programs have refined and revamped quality of life where there has been an increase of $10 \%$ in life expectancy and about $66 \%$ decrease in infant mortality rate. Eradication of diseases like smallpox and polio (partially) worldwide was only possible due to the implementation of vaccination by every nation [3]. On a broad scale, vaccines are demarcated into 2 groups, one group having live attenuated pathogens while the other group of subunit vaccines, including toxoid vaccines, conjugate vaccines, and carbohydrate vaccines [4]. Since the genomic discovery of SARS-CoV, vaccine production and trials began immediately for the development of protein-based, RNA-based, and viral vector vaccines at a pandemic pace [5]. These vaccines bear the antigen-presenting cells (APCs), which present epitopes of SARS-CoV-2 through the major histocompatibility complex I (MHC class I) in humans. The MHC cells in the newly formed CD8+ cells to destroy the invading infected cells through their cytolytic activity. Moreover, T helper 1 cells (Th1) are activated via MHC class II, which further strengthens the "CD8" + cellular reaction. Production of $\mathrm{T}$ helper 2 cells (Th2) and follicular helper cells initiate the formation of viral antibodies; collectively strengthening immunity through B-cell and T-cell activities [6].

\section{Background of Corona Virus Disease}

COVID-19 was first recognized as pneumonia in December 2019, which started to spread among people working or living near the human seafood market. Upon a throat swab test, it was recognized as a novel form of coronavirus by WHO which was named "SARS-COV-2" and infection is known as "COVID-19". During February 2020, the average mortality rate had risen to $2.1 \%$ in China [7]. In February 2020, COVID-19 had spread to 46 countries of the world. Human to the human mode of transmission was hinted and evidence suggested that the viral agent transferred through droplets in close contact. At that time, the calculated reproductive number $\left(\mathrm{R}_{0}\right)$ was ranging from 2.20 to 3.58 . The incubation period of invading virus ranged from 1-14 days and an average person suffered symptoms after 12.5 days of contact. The possibility of asymptomatic carriers was also calculated [8]. By $11^{\text {th }}$ March 2020, COVID-19 was announced pandemic by the WHO. The disease was suspected to be disastrous in people associated with conditions like diabetes, chronic heart diseases, obstructive pulmonary disease, and renal failure [9]. General indications of COVID-19 may include fever, myalgia, fatigue, dyspnea, dry cough, tightening of the chest, nausea, and vomiting [10]. Severe patients may display falling blood oxygen saturation (below 93\%), decreased respiration (less than 30 per minute), while critical patients may undergo respiratory failure, organ dysfunction, or septic shock [2]. Clinically, COVID19 may manifest lymphopenia and leukopenia along with elevated creatinine kinase and lactate dehydrogenase. Abnormal levels of procalcitonin, aspartate aminotransferase, alanine aminotransferase, and D-dimer have also been observed. Levels of certain cytokines and chemokines were also affected in COVID-19 patients [11].

\section{Vaccine Candidates and Trials}

COVID-19 has proved to be a threat to public health on a global level, asserting an impending need to formulate an operative vaccine. The manufacturing of a productive vaccine is critical in the current conditions of the pandemic. Vaccine candidates can provide a good understanding of the development of immunity against the spike protein of SARS-COV-2, which can form an immunological basis for vaccine production in the future [12]. During this pandemic, it is absolute to shortlist vaccine candidates having certain qualities. The phase 1 trials were based on the 


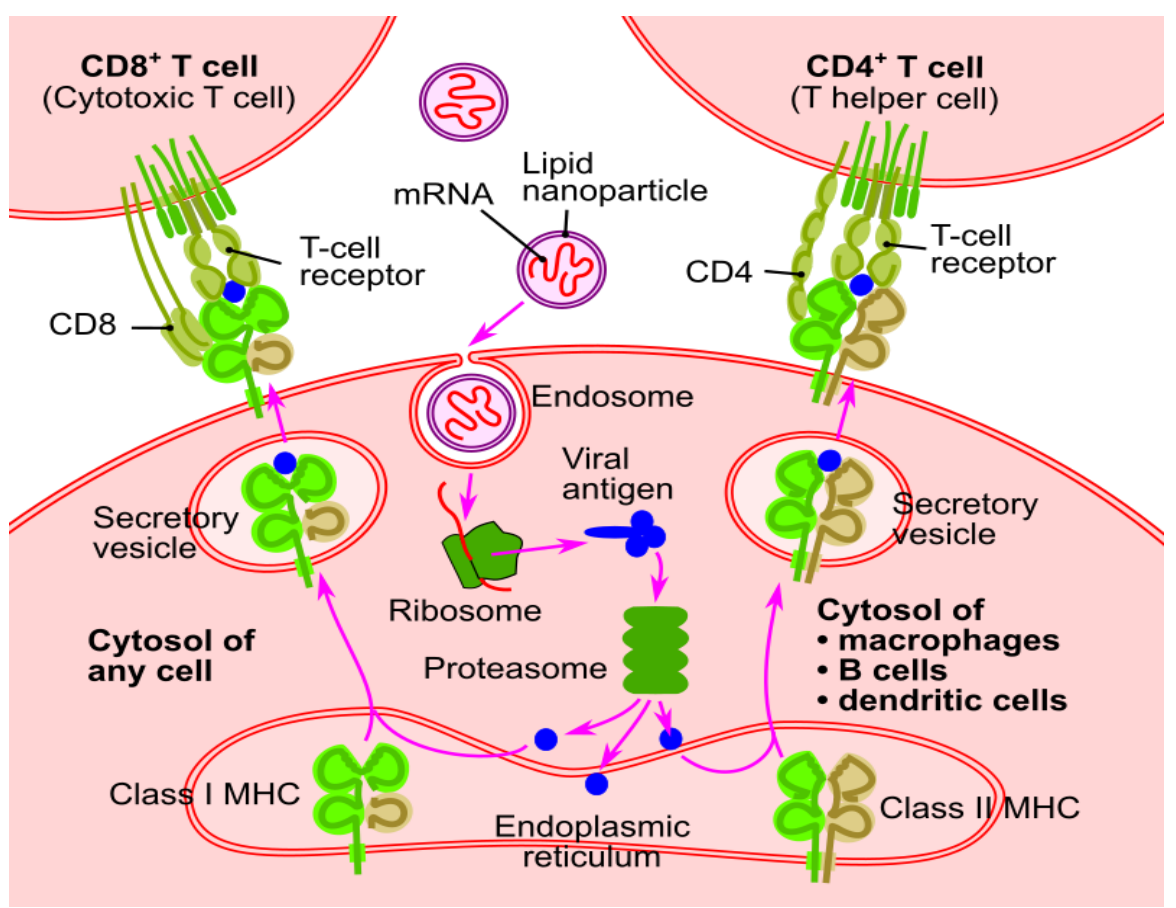

Fig. 1 An illustration of the mode of action of RNA vaccine [57].

Available from: https://commons.wikimedia.org/wiki/File:RNA_vaccine-en.svg

results obtained from animal immunogenetic tests, and the trials were expanded to test human immunogenetic qualities based on the evidence produced from animal models. Progress to efficacy trials (phases 2 and 3 ) bore additional evidence of the safety of animals injected with a limited dose of vaccine with fruitful effects. Health evaluation of candidates along with studies in animals provided a route to vaccine production with minimum risk and accelerated availability of the COVID-19 vaccine [13]. University of Oxford and AstraZeneca conducted trials of AZD1222 "adenovirus vaccine". After phase-1, two-dose administration of vaccine was asserted with the standard dose of $5 \times 10^{10}$ particles per dose, each administered 28 days apart. In total, 19 trials were going on all around Britain. A follow-up of 2 trials of 11,636 participants was conducted within four months consisting of $87.8 \%$ people aged between $18-55$, and $60.5 \%$ participants were female. No one was admitted to hospitals for COVID-19 related symptoms, while some symptoms were seen in participants of the control group [14]. The findings of phase 1-2 clinical trials of the AZD1222 vaccine conducted by the University of Oxford and AstraZeneca supported the hypothesis that a twodose vaccine could increase anti-spike protein production, Fc-mediated functional antibody responses, antibody-dependent neutrophil/ monocyte phagocytosis, complement activation, and natural killer cell activation [15]. Sinovac Biotech Co. Ltd. conducted clinical trials of their inactivated vaccine in Beijing, where they administered $16 \mathrm{SU}$ or $32 \mathrm{SU}$ (SARS-CoV-2 units) in the deltoid muscle, each dose 28 days apart. In total, 36 healthy candidates were chosen for trials, aged between 21-40 having a normal immune system and no chronic disease, they were divided into 3 groups of 12 candidates each. None of the candidates reported a severe reaction to the vaccine, all mild, local symptoms were resolved within 47-72 hours and all systemic symptoms subsided within 24 hours. Seroconversion of $100 \%$ was achieved in 2 groups getting $16 \mathrm{SU}$ on day 42 while seroconversion of $91.1 \%$ was achieved in group 3 getting $32 \mathrm{SU}$ on day 56 [16].

\section{RNA Vaccine Development and Limitations}

With the ascent of the COVID-19 pandemic, an mRNA vaccine was quick to enter clinical preliminaries [17]. For the vaccine development, RNA introduces himself as a flexible and 
encouraging stage (Fig. 1). The RNA-vaccine is known for encoding the required sequence of virus. These RNA-vaccines are less susceptible to the host genomic mixing and act as anti-vector immunity, that's why these vaccines propose incredible potential as primers for the COVID-19 vaccine [18]. BNT162b1 is an mRNA vaccine that encodes the trimers of RBD; present on the spikes of the SARSCoV-2 made of glycoprotein. This mRNA vaccine is the lipid minute formulated particle vaccine, which after vaccination results in vigorous immunogenicity [19]. Nowadays RNA vaccines proved to be more favorable than other types. It has the advantage that RNA vaccines can handle viral infection, develop immunogenicity, and quick production can be made possible [20]. DNA vaccine has developed into a nonviolent and steady technology for vaccination against SARSCOV-2 [21]. In SARS COV-2, the interference of DNA vaccine encodes the S-protein of the virus that produces $\mathrm{T}$-cell and protective immunity and generates NAb responses. The limitations of the DNA vaccine are that it needs precise delivery devices for attaining a good immune response [19]. To obtain a better immune response to SARSCOV-2 infection, DNA plasmids are used to encode immunogenic antigens and deliver them to the host's cells. [22]. Because of the speedily global spread of this novel coronavirus, messenger RNA vaccines for human clinical trials are sometimes not possible to make as a safe and effective vaccine for SARS-COV-2 in this pandemic time to overcome the increasing factor of mortality because of the increasing number of deaths due to this novel coronavirus [23].

\section{Host Infection and Immune Response}

COVID-19 is considered the most arduous challenge in the world and for that, the worldwide vaccination program is applied effectively. By overriding virusinduced innate immune repression and assisting adaptive immunological activation, COVID-19 vaccination improves immunity and viral control. Immunity plays an important role in the later stages of COVID-19, as it aids immunopathology efficiently. This happens because of the maximum production of cytokines by macrophages [24]. One study was made to observe the influence of vaccines on the immune response. The people who recovered from COVID19 had $100 \% \mathrm{CD}^{+} \mathrm{T}$ cells having $\mathrm{S}$ protein specific, whereas $70 \%$ had $\mathrm{CD}^{+} \mathrm{T}$ cells having $\mathrm{S}$ protein-specific in the circulation. These findings suggest that $\mathrm{T}$ lymphocytes play a defensive role in the host's defense against Coronavirus-2, which causes severe acute respiratory syndrome [25]. In the host immune response, inactive immune cells in circulation lead the host to self-destruct (Fig. 2). As a result, the COVID-19 becomes more severe [26]. More observations made from people who recovered from COVID-19 recommend that the specific antibody response against the infection has a short life. In these infected persons, covid specific antibodies that have IgM and IgA effects, lasted $<6$ months. This causes a lack of B-cells and memory Tcells in such people. In the future, such vaccine strategies should be made, which enhance T-cell response resulting in robust long-term memory. By applying such strategies that have memory T-cells provide good safety and boosts the general and systemic T-cell response [27].

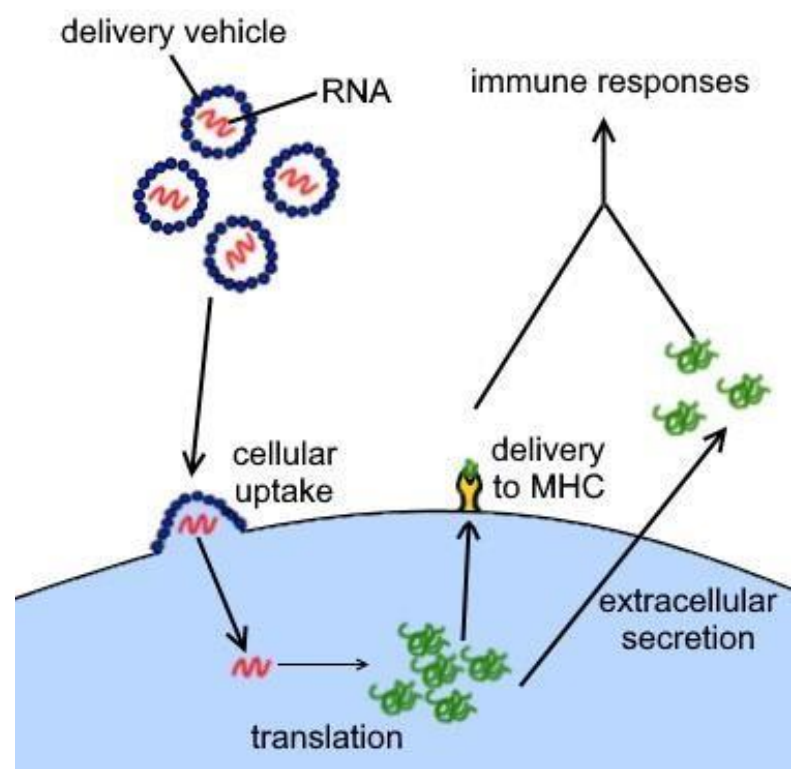

Fig. 2 RNA vaccine illustration [58]. Available from: https://commons.wikimedia.org/wiki/File:RNA_vaccine_i llustration_(en).jpg

\section{Efficacy of Available Vaccines}

The efforts around the globe to develop an efficient vaccine that could combat the SARS-CoV-2 are on track [28]. The aged people and people with preexisting conditions or diseases are more prone to the virus. To get the desired outcome of the vaccine, two 
Science Letters 2022; 10(1):1-8

Table 1 Comparative analysis of several commercial COVID vaccines.

\begin{tabular}{|c|c|c|c|}
\hline Types of vaccines & Brands & Reported side effects & Efficacy $(\%)$ \\
\hline \multirow{3}{*}{ Viral vector } & Johnson & \& Pain at site of injection, headaches, \& flu-like symptoms [36] & 66 [35] \\
\hline & Johnson & & \\
\hline & AstraZeneca & Diarrhea, fatigue, headache, chills, nausea [34] & $70[37]$ \\
\hline Protein-based & Novavax & - & $60-86$ [35] \\
\hline \multirow{2}{*}{ mRNA vaccines } & $\begin{array}{l}\text { Pfizer- } \\
\text { BioNTech }\end{array}$ & $\begin{array}{l}\text { Pain at site of injection, headaches, Flu-like symptoms, fever \& } \\
\text { fatigue [38] }\end{array}$ & $95[31,39]$ \\
\hline & Moderna & $\begin{array}{l}\text { Rashes [40], vomiting, fever, headache, muscle aches [34] } \\
\text { Nausea }\end{array}$ & $\begin{array}{l}94.5[37,41, \\
42]\end{array}$ \\
\hline \multirow{2}{*}{ Inactivated vaccines } & Sinopharm & Headache, fever, pain at the injection site [34] & $79.34[34]$ \\
\hline & Sinovac & - & $50-91[37]$ \\
\hline
\end{tabular}

ways can be followed: direct vaccination or vaccinating people around the vulnerable people so that the elderly people can be saved from the transmission of the virus [29]. The trials of OxfordAstraZeneca revealed that the people who got vaccinated with a small dose shot supported by the standard dose after four-week interval showed $90 \%$ efficacy [30]. Pfizer BioNTech vaccine studies and trials showed its efficacy to be $52 \%$ between the two doses [31]. While the Sinopharm vaccine provides $79 \%$ protection against the disease and hospitalization. It was the first vaccine authorized by WHO that can be used in an emergency. Sinopharm and AstraZeneca can provide herd immunity as it gives $100 \%$ protection against severe COVID-19 [32]. The people aged above 65 years showed $94 \%$ effectiveness with complete vaccination and 64\% protection when partially vaccinated with Moderna and AstraZeneca vaccines [43]. Pfizer and Moderna vaccines have been proved to be the most effective against COVID-19 (Table 1) [34].

\section{Success of COVID-19 Vaccines Against Delta-variant}

The delta is the form of SARS COVID-2. It's much more contagious than the alpha variant. First It was detected in mid-April 2020 in India after which it got spread all over the world due to traveling from India. To study the effectiveness of the vaccine against delta variant, two methods were conducted; First by using test-negative case-control design to approximate potency of disease caused by both delta and alpha variant. The second was done by estimating the cases of patients diagnosed with delta variants. According to assumption, if the vaccine is more effective towards alpha variant, then delta variant cases could be much higher. The results were taken by genome sequencing method and PCR to test three genes such as spike, nucleocapsid, and open reading frame $1 \mathrm{ab}$ for identifying both variants. Bernel et al. reported that the effectiveness of the first vaccine was higher in people with alpha variant (48.7 $\%)$ and much lower in people with delta variant $(30.7 \%)$ though the result of the vaccine was similar among both, and difference between the effectiveness next the $2^{\text {nd }}$ dose of vaccination either ChAdOx1 nCoV-19 vaccine or BNT162b2 was lower as it was $88.0 \% / 67.0 \%$ with the delta variant and $93.5 \% / 74.5 \%$ with the alpha variant. Overall, the reduced effectiveness with one dose can aid the effort to take two doses of vaccine [43].

\section{Contribution by Various Countries}

After the recognition of the causative agent of COVID-19, pharmaceutical groups inflate attempts for vaccine preparations. Moderna Inc. evolved its first mRNA vaccine and conducted its first clinical testing in the US. Other vaccines that are being developed by different countries are inactivated, subunit, DNA based, replicating viral vector-based, and live attenuated vaccines [44]. Canada and South Korea are conducting trials for DNA-based vaccines while Germany and UK are processing mRNA vaccines $[44,45]$. In countries, like Pakistan vaccine administration is a most important challenge as several conspiracy theories stand in the way of vaccines, like the polio vaccine. Extensive lockdown is impossible because of economic reasons [46]. In February 2021, Pakistan received the COVID-19 vaccine prepared by a Chinese company, Sinopharm after being reported fewer cases in 2020 [47, 48]. 


\section{Access and Equity}

Globally, with an immense number of people getting the coronavirus vaccine, a couple of countries have effectively begun the execution of vaccine certification which indicates available confirmations attesting coronavirus immunization. The advantage of this certification, the government contends, is permission to travel, and ensuring personal and public safety $[49,50]$. Considering all the sources, for the global distribution of the vaccination, there are some inadequate efforts to support the world widely the accession to the coronavirus vaccine (Table 1). It is estimated that almost $25 \%$ of the total populace might not probably have access to vaccines until no less than 2022 [51]. Equity in terms of vaccination is quite important. This should be prioritized and considered first and foremost. This considering is due to the uneven distribution and uneven load of the infection and mortality by discrimination of color and low-income societies. On the side of COVID-19 pandemic, this is quite important to follow up on the virus and better use of the vaccine to keep the viral influence down. This indicates that taking "vaccination campaigns" to societies has been hardhit for a truly lengthy period [52]. According to a recent analysis, various countries have made premarket purchase commitments totaling 7.48 billion doses between November 15 and December 2020. On the front, 13 vaccine manufacturers are there to produce 7.48 billion vaccine doses. The highincome countries purchase more doses of vaccines according to the need of their population for future securement in case of this upgrown pandemic. In this regard, governments and manufacturers need to take strict notice of this. They may also need to give much-needed declarations for impartial distribution of vaccines by more transparency and accountability upon these unfavorable decisions [53].

\section{Strategies Behind Vaccine Operation}

With the advancements in molecular biology research, different strategies have been utilized to develop different vaccine types like attenuated, dead, protein type, RNA/DNA based. While some have been tested in the animal specimen, others have passed the stage to the clinical trials, and some have already come to the market [54]. The receptorbinding area of spike protein has been proven as an
Table 2 Income-based distribution of vaccines.

\begin{tabular}{lc}
\hline \multicolumn{1}{c}{ Countries } & Doses \\
\hline High-income-countries (EU) & 3.85 \\
United States & 0.80 \\
Japan, Australia \& Canada & 1.00 \\
Low-income-countries & 2.34 \\
\hline
\end{tabular}

Note: The numbers of doses are out of 7.481 billion.

effective source of neutralizing antibodies [55]. The S-protein is an important target for combating the virus. It has also been observed that the antibodies produced against the S-protein are lifelong and more effective as it is observed in recovered patients [56]. Nanotechnology has also made way to target viruses using nanoparticles as gene carriers [57]. Nucleic acid vaccines are the traditional vaccines. These are the most prepared type of vaccines because of their safety and feasibility of mass production. With advantages, it also has some drawbacks like a double dose of the vaccine [30]. The whole spectrum of vaccines and vaccination strategies will eventually help to gain herd immunity against the SARS-COV2 [54].

\section{Awaiting DNA Vaccines}

DNA vaccines are made up of genes or fragments of genes. The antigens are delivered into the body of the host using a DNA plasmid vector. It not only stimulates cell-mediated immunity but also humoral immunity. [22]. The DNA vaccines under investigation have been observed to be producing neutralizing antibody effect when the spike protein of the virus is targeted [53]. The DNA vaccines in trials have different approaches like using plasmid coding DNA and the use of hybrid transporter protein to induce an immune response. The route of administration is also uncommon, like the oral route or intradermal electroporation [54]. Most of the vaccines target the $\mathrm{S}$ glycoprotein of the virus. The DNA vaccine under development also targets the spike protein and showed promising results when tried on mice, guinea pigs, and macaque, as the viral load and the lung infection in monkeys was decreased when infected again after 9 weeks of vaccination. It also can neutralize antibodies [55]. The manufacturers of ZyCov-D have claimed that this DNA plasmid vaccine has shown promising results when tested in animal models intradermally. The vaccination resulted in neutralizing antibodies and Th-1 response [58]. 


\section{Conclusions}

COVID-19 at its full blossom has been hosted by many countries and many others are still serving the mighty Covid-19. This demands, to take up the framework of WHO's guidelines, particularly formulated regarding COVID-19 and to take precautionary measures at a satisfactory level. No question can arise at the point that vaccination preparation is a long-drawn-out process and can extend to the period of 5 to 10 years. The currently available and clinically verified vaccines, which are also supplied in countries across the globe are mRNA vaccines, like Sinopharm, AstraZeneca, Pfizer, and Sinovac. Now, the efforts to make DNA vaccines continue in a great hustle, which optimistically ensures its availability in the market, in a short time. Likewise other vaccines, COVID19 vaccines also have side effects, while allaying the COVID-19. These side effects are muscular pain, headaches, high temperature, and fatigue. Though, the vaccine preparation and human vaccination are and will remain a challenge and cumbersome process; because of the unsettled queries, superstitions of people, conspiracies against the vaccine, and low budgeted accounts of many countries and pockets of many people, but still the vaccine has successfully pinned public's hope to a corona-free future.

\section{Conflict of Interest}

The authors declare that they have no conflict of interest

\section{References}

[1] Singhal T. A review of coronavirus disease-2019 (COVID-19). Indian J Pediatr 2020; 4:281-286.

[2] Raza SM, Sajjad T, Fatima SK, Iqbal MF. Novel corona virus and veterinary perspective: a review. Sci Lett 2021; 2:65-71

[3] Bloom DE. The value of vaccination. In: Hot Topics in Infection and Immunity in Children. VII Springer, New York, NY 2011; 697:1-8.

[4] Pulendran B, Ahmed R. Immunological mechanisms of vaccination. Nat Immunol 2011; 6:509-517.

[5] Haynes BF. A New Vaccine to Battle Covid-19. N Engl J Med 2021; 5:470-471.

[6] Borah P, Deb PK, Al-Shar'i NA, Dahabiyeh LA, Venugopala KN, Singh V, et al. Perspectives on RNA vaccine candidates for COVID-19. Front Mol Biosci 2021; 8:1-18.

[7] Harapan H, Itoh N, Yufika A, Winardi W, Keam S, Te $\mathrm{H}$, et al. Coronavirus disease 2019 (COVID-19): A literature review. J Infect Public Health 2020; 5:667-673.

[8] Guan WJ, Ni ZY, Hu Y, Liang WH, Ou CQ, He JX, et al. Clinical characteristics of coronavirus disease 2019 in China. N Engl J Med 2020; 18:1708-1720.

[9] Rahmani AM, Mirmahaleh SY. Coronavirus disease (COVID-19) prevention and treatment methods and effective parameters: A systematic literature review. Sustain Cities Soc 2020; 64:102568-82.

[10] Dong X, Cao YY, Lu XX, Zhang JJ, Du H, Yan YQ, et al. Eleven faces of coronavirus disease 2019. Allergy 2020; 7:1699-1709.

[11] He F, Deng Y, Li W. Coronavirus disease 2019: What we know? J. Med. Virol 2020; 7:719-725.

[12] Khalaj-Hedayati A. Protective immunity against SARS subunit vaccine candidates based on spike protein: lessons for coronavirus vaccine development. J Immunol Res 2020; 2020:1-11.

[13] Graham BS. Rapid COVID-19 vaccine development. Science 2020; 6494:945-6.

[14] Knoll MD, Wonodi C. OxfordAstraZeneca COVID-19 vaccine efficacy. Lancet 2021; 10269:72-74.

[15] Barrett JR, Belij-Rammerstorfer S, Dold C, Ewer KJ, Folegatti PM, Gilbride C, et al. Phase 1/2 trial of SARSCoV-2 vaccine ChAdOx $1 \mathrm{nCoV}-19$ with a booster dose induces multifunctional antibody responses. Nat Med 2021; 2:279-288.

[16] Lin J, Zhang JS, Su N, Xu JG, Wang N, Chen JT, et al. Safety, and immunogenicity from a phase I trial of inactivated severe acute respiratory syndrome coronavirus vaccine. Antivir 2007; 7:1107-1113.

[17] Fuller DH, Berglund P. Amplifying RNA vaccine development. N Engl J Med 2020; 25:2469-2471.

[18] Borah P, Deb PK, Al-Shar'i NA, Dahabiyeh LA, Venugopala KN, Singh V, Shinu P, et al. Perspectives on RNA vaccine candidates for COVID-19. Front Mol Biosci 2021; 8:1-18.

[19] Mulligan MJ, Lyke KE, Kitchin N, Absalon J, Gurtman A, Lockhart S, et al. Phase I/II study of COVID-19 RNA vaccine BNT162b1 in adults. Nature 2020; 7830:589593.

[20] Zhou P, Li Z, Xie L, An D, Fan Y, Wang X, et al. Research progress and challenges to coronavirus vaccine development. J Med Virol 2021; 2:741-754.

[21] Tsunetsugu-Yokota Y, Ohnishi K, Takemori T. Severe acute respiratory syndrome (SARS) coronavirus: application of monoclonal antibodies and development of an effective vaccine. Rev Med Virol 2006; 2:117-131.

[22] Silveira MM, Moreira GM, Mendonça M. DNA vaccines against COVID-19: Perspectives and challenges. Life Sci 2020; 267:1-7.

[23] Wang F, Kream RM, Stefano GB. An evidence-based perspective on mRNA-SARS-CoV-2 vaccine development. Med Sci Monit 2020; 26:1-8.

[24] Jeyanathan M, Afkhami S, Smaill F, Miller MS, Lichty BD, Xing Z. Immunological considerations for COVID19 vaccine strategies. Nat Rev Immunol 2020; 20:615632.

[25] Grifoni A, Weiskopf D, Ramirez SI, Mateus J, Dan JM, Moderbacher CR, et al. Targets of $\mathrm{T}$ cell responses to 
SARS-CoV-2 coronavirus in humans with COVID-19 disease and unexposed individuals. Cell 2020; 7:14891501.

[26] Seth S, Batra J, Srinivasan S. COVID-19: Targeting Proteases in Viral Invasion and Host Immune Response. Front Mol Biosci 2020; 7:1-9.

[27] Channappanavar R, Zhao J, Perlman S. T cellmediated immune response to respiratory coronaviruses. Immunol Res 2012; 59:118-128.

[28] Paltiel AD, Schwartz JL, Zheng A, Walensky RP. Clinical Outcomes of A "COVID-19" Vaccine: Implementation Over Efficacy. Health Aff 2021; 1:4252.

[29] Lipsitch M, Dean NE. Understanding COVID-19 vaccine efficacy. Science 2020; 6518:763-5.

[30] Hung IF, Poland GA. Single-dose Oxford-AstraZeneca "COVID-19" vaccine followed by a 12 week booster. Lancet 2021; 10277:854-855.

[31] Mahase E. Covid-19: Pfizer vaccine efficacy was 52\% after first dose and $95 \%$ after second dose, paper shows. Br Med J 2020; 371:m4826.

[32] Ghiasi N, Valizadeh R, Arabsorkhi M, Hoseyni TS, Esfandiari K, Sadighpour T, et al. Efficacy, and side effects of Sputnik V, Sinopharm and AstraZeneca vaccines to stop COVID-19, a review and discussion. Immunopathol Persa 2021; 2:1-5.

[33] Tenforde MW. Effectiveness of Pfizer-BioNTech and

Moderna vaccines against COVID-19 among hospitalized adults aged $\geq 65$ years — United States, January-March 2021. Morb Mortal Wkly Rep 2021; 18:674-679.

[34] Siddique S, Ahmed S. COVID-19 vaccines in Pakistan: efficacy, adverse effects and availability. J Islamabad Med Dent College 2021; 2:125-30.

[35] Mahase E. Covid-19: Novavax vaccine efficacy is $86 \%$ against UK variant and 60\% against South African variant. Br Med J 2021; 372:n296.

[36] Livingston EH, Malani PN, Creech CB. The Johnson \& Johnson vaccine for COVID-19. Jama 2021; 15:1575.

[37] Kim JH, Marks F, Clemens JD. Looking beyond COVID-19 vaccine phase 3 trials. Nat Med 2021; 2:205211.

[38] El-Shitany NA, Harakeh S, Badr-Eldin SM, Bagher AM, Eid B, Almukadi H, et al. Minor to moderate side effects of Pfizer-BioNTech "COVID-19" vaccine among Saudi residents: A retrospective cross-sectional study. Int J Gen Med 2021; 14:1389- 1401.

[39] Chagla Z. The BNT162b2 (BioNTech/Pfizer) vaccine had $95 \%$ efficacy against COVID-19 $\geq 7$ days after the 2nd dose. Ann Intern Med 2021; 2:JC15.

[40] Malayala SV, Mohan G, Vasireddy D, Atluri P. Purpuric rash and thrombocytopenia after the mRNA-1273 (Moderna) COVID-19 vaccine. Cureus 2021; 3:1-4.

[41] Mahase E. Covid-19: Moderna applies for US and EU approval as vaccine trial reports $94.1 \%$ efficacy. Br Med J 2020; 371:m4750.

[42] Mahase E. Covid-19: Moderna vaccine is nearly 95\% effective, trial involving high risk and elderly people shows. Br Med J 2020; 371:m4471.
[43] Lopez Bernal J, Andrews N, Gower C, Gallagher E, Simmons R, Thelwall S, Stowe J, Tessier E, Groves N, Dabrera $\mathrm{G}$, et al. Effectiveness of COVID-1 vaccines against the B.1.617.2 (Delta) variant. N Engl J Med 2021; 385:e92.

[44] Harapan H, Wagner AL, Yufika A, Winardi W, Anwar S, Gan AK, Setiawan AM, Rajamoorthy Y, Sofyan H, Mudatsir M. Acceptance of a COVID-19 vaccine in Southeast Asia: a cross-sectional study in Indonesia. Front Public Health 2020; 8:381.

[45] Li Y, Tenchov R, Smoot J, Liu C, Watkins S, Zhou Q. A comprehensive review of the global efforts on COVID19 vaccine development. ACS Cent Sci 2021; 4:512-533.

[46] Khan YH, Mallhi TH, Alotaibi NH, Alzarea AI, Alanazi AS, Tanveer N, Hashmi FK. Threat of COVID-19 vaccine hesitancy in Pakistan: the need for measures to neutralize misleading narratives. Am J Trop Med Hyg 2020; 2:603-604.

[47] Abid K, Bari YA, Younas M, Tahir Javaid S, Imran A. Progress of COVID-19 Epidemic in Pakistan. Asia Pac J Public Health 2020; 32:154-156.

[48] Mumtaz S, Gul S. Third wave of COVID-19 Epidemic in Pakistan. Life Sci 2021; 2:83-83.

[49] Wilson K, Flood CM. Implementing digital passports for SARS-CoV-2 immunization in Canada. Can Med Assoc J 2021; 14:486-488.

[50] Osama T, Razai MS, Majeed A. COVID-19 vaccine passports: access, equity, and ethics. Br Med J 2021; 373:n861.

[51] Lazarus JV, Ratzan SC, Palayew A, Gostin LO, Larson HJ, Rabin K, Kimball S, El-Mohandes A. A global survey of potential acceptance of a COVID-19 vaccine. Nat Med 2021; 27:225-228.

[52] Domingo KB, Petersen M, Havlir D. Taking vaccine to where the virus is-equity and effectiveness in coronavirus vaccinations. JAMA Health Forum 2021; 2:e210213.

[53] So A D, Woo J. Reserving coronavirus disease 2019 vaccines for global access: cross sectional analysis. $\mathrm{Br}$ Med J 2020; 371:m4750.

[54] Frederiksen LS, Zhang Y, Foged C, Thakur A. The long road toward COVID-19 herd immunity: vaccine platform technologies and mass immunization strategies. Front Immunol 2020; 11:1-26.

[55] Pandey SC, Pande V, Sati D, Upreti S, Samant M. Vaccination strategies to combat novel corona virus SARS-CoV-2. Life sci 2020; 256:1-9.

[56] Li YD, Chi WY, Su JH, Ferrall L, Hung CF, Wu TC. Coronavirus vaccine development: from SARS and MERS to COVID-19. J Biomed sci 2020; 1:1-23.

[57] Rego GN, Nucci MP, Alves AH. Current clinical trials protocols and the global effort for immunization against sars-cov-2. Vaccines 2020; 3:1-44.

[58] Malik JA, Mulla AH, Farooqi T, Pottoo FH, Anwar S, Rengasamy KR. Targets, and strategies for vaccine development against SARS-CoV-2. Biomed Pharmacother 2021; 137:1-11. 